\title{
Massive Hemothorax Following Thrombolysis With rtPA in a Stroke Patient With Undiagnosed Rib Fractures
}

\author{
Tomas Belzunegui ${ }^{\mathrm{a}, \mathrm{b}, \mathrm{c}}$, Carlos Beaumont ${ }^{\mathrm{a}}$, Clint Jean Louis ${ }^{\mathrm{a}}$, Ana Cabodevilla ${ }^{\mathrm{a}}$
}

\begin{abstract}
The majority of strokes are of ischaemic origin. Thrombolysis has led to a radical change in the outcome of these patients as far as management and prognosis. The main objective is the opening up of the occluded artery and early reperfusion of brain tissue. Only $2 \%$ to $4 \%$ of patients with acute ischemic stroke receive thrombolytic therapy resulting from the current strict inclusion criteria among other issues. Safety of intravenous and intraarterial thrombolysis in off-label situations is controversially discussed. The most feared complication related to the use of rtPA is intracerebral haemorrhage. Our case is an 84-year-old man who after receiving rtPA in the acute phase of a stroke, presented a massive hemothorax secondary to rib fractures which had not been previously diagnosed at admission. The neurological course was excellent and the hemothorax was resolved after inserting chest drainage. To obtain a meaningful database, a registry for off-label thrombolysis should be created.
\end{abstract}

Keywords: Thrombolysis; Stroke; Hemothorax; Rib fractures

\section{Introduction}

Treatment of ischemic stroke dramatically changed after the introduction of thrombolytic therapy in 1995 . However, only $2 \%$ to $4 \%$ of the patients receive intravenous thrombolysis mainly as a result of the short time window and the strict inclusion criteria. As experience with tissue plasminogen activator (tPA) increases, new situations emerge in which the

\footnotetext{
Manuscript accepted for publication April 24, 2013

${ }^{a}$ Accident and Emergency Department, Hospital of Navarre, Spain

${ }^{\mathrm{b}}$ Department of Health, Public University of Navarre, Spain

${ }^{\mathrm{c}}$ Corresponding author: Tomas Belzunegui, Accident and Emergency

Department, Hospital of Navarre, Spain.

Email: tomas.belzunegui@unavarra.es
}

doi: http://dx.doi.org/10.4021/jmc1250w safety of thrombolysis remains unknown. Moreover, the inadvertent or deliberate off-label use of thrombolysis has led to a requestioning of some of the stated exclusion criteria. In these 10 years of experience with tPA, many articles have been published on doubtful situations in which patients were treated.

\section{Case Report}

An 84-year-old man was brought into the emergency department by the prehospital emergency services after falling down in relation to a sudden onset of weakness in both left extremities. The patient arrived 50 minutes after the onset of symptoms. His vital signs were: blood pressure 158/76 $\mathrm{mmHg}$, heart rate 76 beats per minute $(\mathrm{bpm})$ and capilary glycemia 129 . His neurological examination revealed deviation of right labial commissure, dysarthria, hypoesthesia and paresia in the left arm and leg (2/5 in the arm and 3/5 in the leg), with left Babinski and a NIHSS of 12.

The EKG showed sinus rhythm at $80 \mathrm{bpm}$. A head CT scan ruled out hemorrhage. Doppler studies of the supraaortic trunk showed normal carotid flow, while transcranial doppler studies revealed an occlusion (TIBI 1 pattern) of the right middle cerebral artery (Fig. 1).

Given the time of evolution and the absence of contraindications, endovenous thrombolysis with rtPA was performed, after which clinical improvement was observed (NIHSS: 5) and a change in doppler pattern with the opening up of the occluded artery (TIBI 4, with systolic velocities of $180-200 \mathrm{~cm} / \mathrm{second}$ ) (Fig. 2).

Transcranial eco-doppler (GE Vivid 7 Pro, GE Medical Systems, Horten Norway) was performed using a 1.5 - 4 $\mathrm{MHz}$ transcranial probe from both temporal bone windows.

After two days the patient referred pain in the right costal margin, with no dyspnea. He recalled falling on the day of admission. A chest radiograph revealed 3 rib fractures (Fig. 3) and a massive hemothorax (Fig. 4) requiring chest drainage (Fig. 5). No complications were observed during his clinical course.

On discharge the patient's NIHSS: 0 points, with only slight limitation in his left hand (Rankin 1 Barthel 85). 


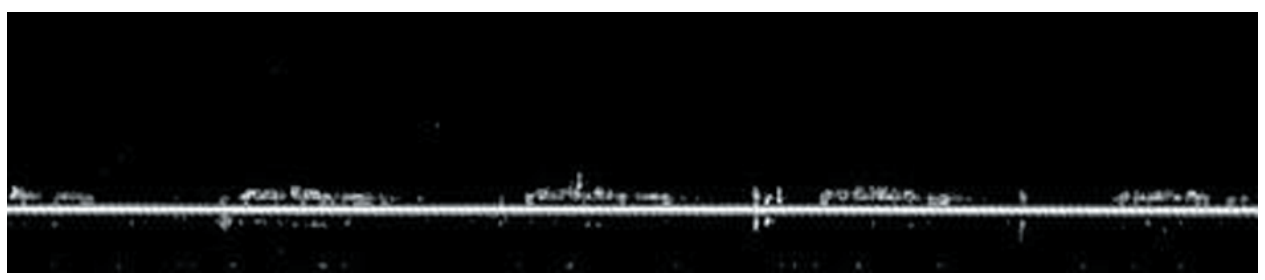

Figure 1. Systolic spikes of variable velocity and duration. Absent diastolic flow during all cardiac cycles.

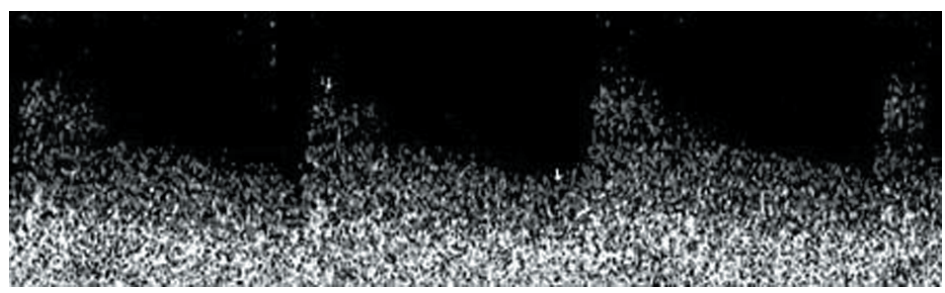

Figure 2. Systolic velocity: $180-200 \mathrm{~cm} / \mathrm{s}$.

\section{Discussion}

The majority of strokes are of ischaemic origin provoked by a thrombus lodged within an intracraneal artery. Thrombolysis reduces the proportion of dead patients or patients dependent for activities of daily living [1]. Recombinant tissue plasminogen activator (rt-PA), is the only approved drug indicated in the acute phase of stroke [2].

Treatment with rtPA has proved to be effective and secure in the first three hours after the onset of the stroke, with a reduction in mortality and functional dependency [3].

Not many patients benefit from this agent mainly because of the margin time for treatment. Longer door-to-needle time has been shown to be associated with higher rates of intracerebral hemorrhage [4]. Therefore it is important to carefully select candidates for thrombolysis. Exclusion criteria attempt to minimize the risk of bleeding.

Different haemorrhagic related complications have been

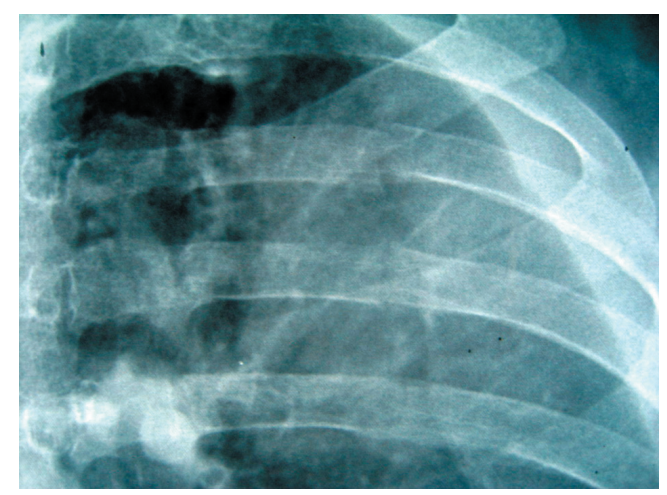

Figure 3. An anteroposterior radiograph shows a radiolucent line without displacement at the posterior portion of three ribs. described in relation to treatment with rtPA [5-10]. Among the requirements for treatment, the patient should show no evidence of active bleeding or acute trauma (fracture) on examination [2]. In our case there was no clinical evidence of trauma (the initial physical examination was normal and the patient did not refer pain or dyspnea). Thus thrombolysis was administered despite the rib fractures which remained undiagnosed initially.

The patient's neurological evolution was excellent, despite suffering from the hemothorax which was resolved with a chest drain. Should the fracture have been diagnosed beforehand the patient would surely not have received the undeniably beneficial outcome following thrombolysis.

From this we do not want to suggest that the presence of a rib fracture should not be considered as criteria for exclusion from thrombolytic therapy, as it is a potentially severe complication. We simply want to share our experience give the particular outcome of this patient. When therapy with

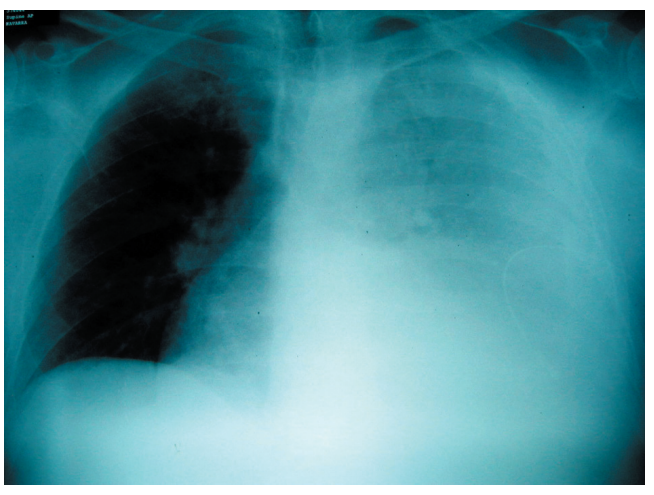

Figure 4. Posteroanterior chest radiograph at presentation with the hemothorax. A large left pleural effusion is prominent. 


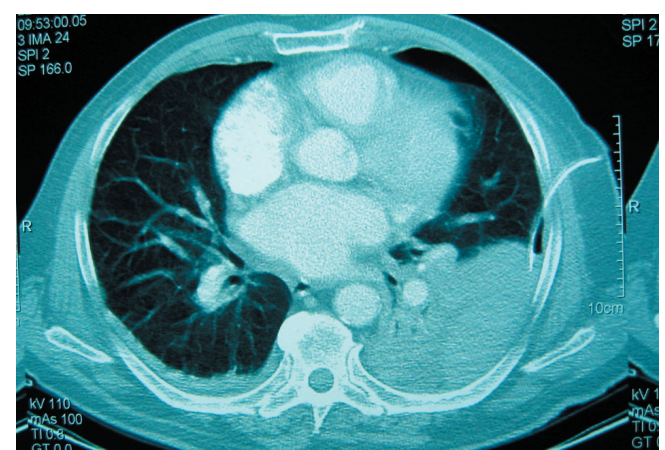

Figure 5. CT scan shows the left hemothorax and the chest drainage.

rtPA was initiated for acute stroke, the contraindications were more restrictive and with time and experience there has been an attempt to increase the number of patients who could benefit from it [11]: for instance, the increase in the margin for therapy to more than three hours $[12,13]$ and its application in patients above 90 years of age [14].

\section{Conclusion}

Selected patients might benefit, however, from thrombolysis in situations not currently considered in the inclusion criteria [15].

\section{References}

1. Wardlaw JM, Murray V, Berge E, Del Zoppo GJ. Thrombolysis for acute ischaemic stroke. Cochrane Database Syst Rev. 20094):CD000213.

2. Adams HP. Thrombolytics in acute ischaemic stroke: a guide to patient selection and optimum use. BioDrugs. 2000;13(2):115-126.

3. Wahlgren N, Ahmed N, Eriksson N, Aichner F, Bluhmki E, Davalos A, Erila T, et al. Multivariable analysis of outcome predictors and adjustment of main outcome results to baseline data profile in randomized controlled trials: Safe Implementation of Thrombolysis in Stroke-MOnitoring STudy (SITS-MOST). Stroke. 2008;39(12):33163322.

4. Fiorelli M, Alperovitch A, Argentino C, Sacchetti ML, Toni D, Sette G, Cavalletti C, et al. Prediction of long- term outcome in the early hours following acute ischemic stroke. Italian Acute Stroke Study Group. Arch Neurol. 1995;52(3):250-255.

5. Hayashi H, Kawamata H, Ichikawa K, Tajima H, Kumazaki T. Rupture of a thoracic aortic aneurysm: a rare adverse reaction following systemic tissue plasminogen activator infusion. Heart Vessels. 2004;19(4):208211.

6. Khawly JA, Ferrone PJ, Holck DE. Choroidal hemorrhage associated with systemic tissue plasminogen activator. Am J Ophthalmol. 1996;121(5):577-578.

7. Kim SH, Choi SH, Song EC, Rha JH, Kim SR, Park HC. Spinal subdural hematoma following tissue plasminogen activator treatment for acute ischemic stroke. J Neurol Sci. 2008;273(1-2):139-141.

8. Kremen SA, Wu MN, Ovbiagele B. Hemopericardium following intravenous thrombolysis for acute ischemic stroke. Cerebrovasc Dis. 2005;20(6):478-479.

9. Shaps HJ, Snyder GE, Sama AE, Rudolph GS. Airway compromise secondary to lingual hematoma complicating administration of tissue plasminogen activator for acute ischemic stroke. Ann Emerg Med. 2001;38(4):447449.

10. Yip TR, Demaerschalk BM. Forearm compartment syndrome following intravenous thrombolytic therapy for acute ischemic stroke. Neurocrit Care. 2005;2(1):47-48.

11. De Keyser J. Thrombolytic therapy for acute ischemic stroke. Neurology. 1997;49(3):900-901.

12. Del Zoppo GJ, Saver JL, Jauch EC, Adams HP, Jr. Expansion of the time window for treatment of acute ischemic stroke with intravenous tissue plasminogen activator: a science advisory from the American Heart Association/ American Stroke Association. Stroke. 2009;40(8):29452948.

13. Hacke W, Kaste M, Bluhmki E, Brozman M, Davalos A, Guidetti D, Larrue V, et al. Thrombolysis with alteplase 3 to 4.5 hours after acute ischemic stroke. N Engl J Med. 2008;359(13):1317-1329.

14. Mateen FJ, Nasser M, Spencer BR, Freeman WD, Shuaib A, Demaerschalk BM, Wijdicks EF. Outcomes of intravenous tissue plasminogen activator for acute ischemic stroke in patients aged 90 years or older. Mayo Clin Proc. 2009;84(4):334-338.

15. Aleu A, Mellado P, Lichy C, Kohrmann M, Schellinger PD. Hemorrhagic complications after off-label thrombolysis for ischemic stroke. Stroke. 2007;38(2):417-422. 